\title{
On Translation Strategies of Culture-Specific Items in Game Localization
}

\author{
Shi Xinyan and Tian Jianguo
}

\begin{abstract}
Translation is of great importance in game localization. During the translation process, some words may cause difficulty in translation as they are unique in game culture. They are either newly created words, or common words with new meanings in the game. Javier Franco Aixelá defined CSIs as "certain items in source texts whose function and connotation involve translation difficulties in their transference to target texts, because of nonexistence of given items or their different textual status in the cultural system of the readers of target texts". Guided by his study on Culture-Specific Items, this paper takes the translation of the created words and neologies in League of Legend as examples to study the detailed translation strategies of Culture-specific items in the fictional game context, so as to offer some help to the improvement of the translation quality of game culture-specific items.
\end{abstract}

Index Terms-Culture-specific Items, translation, game localization, LOL.

\section{INTRODUCTION}

With the advancement of computer science and network techniques, the online game industry steps into a fast-developing period. To attract players from the globe, a game must be localized to adjust the local culture when entering into other countries' game market. In the process of game localization, one crucial step is the translation of the background story. Games are mostly fictional, and some create their own worldview which would possibly include geography, religion, society, and so on. In the depiction of these elements, the approach of neologism and new word creation are used often to produce certain game culture-specific items to stand for new things and new meanings. The understanding and translation of these words is the core to the reconstruction of the game background and game culture, and thus may effectively influence game players' knowledge and interest in the game.

\section{Culture-Specific Items AND LeAGue of LEGENDS}

\section{A. Culture-Specific Items}

In 1999, Susan Bassnett and Andre Lefevere promoted a "cultural turn" in translation in Translation History and Culture, extending the study angel of translation from linguistics to culture [1], [2]. "Cultural turn" means that the focus of translation studies has been shifted from linguistic

Manuscript received August 19, 2019; revised September 12, 2019.

Shi Xinyan and Tian Jianguo are with the Northwestern Polytechnical University, China (e-mail: 1435296889@qq.com, chery.zhai@grapecity.com). and structural equivalence to socio-cultural factors influencing the translation process. Many scholars have made great efforts in proposing a precise definition to cultural turn. Nida (1993: 199) regards cultural translation as "a translation in which the content of the message is changed to conform to the receptor culture in some way, and/or in which information is introduced which is not linguistically implicating the original; opposed to the linguistic translation". Shuttleworth Mark and Moira Cowie (2004: 35) define cultural translation as "a term used informally to refer to types of translation which function as a tool for cross-cultural or anthropological research, or indeed to any translation which is sensitive to cultural as well as linguistic factors".

Under the influence of "cultural turn", words and expressions embodied with culture are payed much attention and certain terms are created for their references [3]. Proposed by the Spanish translator and translation theorist Javier Franco Aixelá, Culture-Specific Items (CSIs) are used most.

Javier Franco Aixelá defined CSIs as "certain items in source texts whose function and connotation involve translation difficulties in their transference to target texts, because of nonexistence of given items or their different textual status in the cultural system of the readers of target texts" [4], and based on his own translation experience, he summarized eleven translation strategies of CSIs translation, they are being repetition, orthographic adaptation, linguistic (non-cultural) translation, extratextual gloss, intratextual gloss, synonymy, limited universalization, absolute universalization, naturalization, deletion, and autonomous creation [5], [6].

Besides Aixelá, many other scholars extended their study on cultural aspects through CSIs. In Toward A Science of Translating, Eugene Nida classified CSIs into five types: ecological culture, material culture, religious culture, social culture and linguistic culture [7], [8].

\section{B. League of Legends}

Developed by American Riot Games, League of Legends (LOL) is a hero-based MOBA competitive online game. It hit the game market in 2009, and is now an international game with up to 27 million active online game players across the world. LOL has a very detailed description of game world architectures, skill settings, hero stories, etc. [9]. The construction of the game worldview has been mature and complete through 10-year's development. Its well-acceptance by Chinese players who are not native English speakers can be evidence proving their satisfaction towards the Chinese translation, making it a good material for study. 


\section{RESEARCH PROCEDURE}

In this paper, the author employed the original English background story of LOL, as well as its Chinese translation as the material source, from which, the author picked out the fictional game CSIs as the study materials.

First, the author will, based on Nida's classification of CSIs, classify the materials into ecological fictional game CSIs, material fictional game CSIs, religious fictional game CSIs, social fictional game CSIs and linguistic fictional game CSIs. Second, the author will match the game translators' ways of dealing with fictional game CSIs to the eleven translation strategies proposed by Aixelá. After the upper mentioned two steps, the author would be able to analyze and draw a conclusion on the connection between the translation strategy adopted and the context of CSIs.

\section{RESULTS AND DISCUSSIONS}

The author picked out 313 game CSIs in total from the background story of LOL, among which 70 are ecologically fictional, 65 are materially fictional, 175 are socially fictional, and the rest 3 are religious. Due to the lack of religious and linguistic CSIs data, the author will not discuss them in this paper.

\section{A. Ecological CSIs}

1) Names of places

Example:

English: The strange effect of those magics would rather alter the course of history. Demacia had been mired in a grueling battle with Noxian forces in the Greenfang Mountains of Northern Valoran.

Chinese: 事实上, 这些魔能的效果将会改变历史前进的 方向。德玛西亚当时正在瓦洛兰北方的绿齿峰与诺克萨 斯的部队进行旷日持久的缠斗。

Translation strategies: orthographic adaptation, linguistic (non-cultural) translation.

"Valoran" is a fictional continent in LOL where several countries have been established. People from different countries in "Valoran" would fight over wealth and land. "Valoran" is a new word created to refer to a fictional continent in LOL, thus it holds no special meaning other than it indicative function, so the translator simply used the strategy of orthographic adaptation to translate it into “瓦洛 兰”.

"Greenfang Mountains" refers to a group of mountains sitting in the northern part of Valoran. It is the battlefield between Demacian and Noxian. Similar to "Valoran", "Greenfang Mountains" is used to indicate the location of the bloody battle. Yet rather than orthographic adaptation, the translator employed linguistic (non-cultural) translation strategy. The reason lies in the other function "greenfang" holds: description. "Ggreenfang" is a compound word of "green" and "fang". It gives a vivid description of the color and the shape of the mountains: the mountains must be green, and the shape of the mountains is alike fangs of a beast, and “绿齿峰” is a perfect reappearance of both the indicative function and the descriptive function of "Greenfang Mountains".
As most of the CSIs selected are newly created words with no other trace of their meanings rather than the text. Their translation situation as well as their translation strategy are the same with "Valoran" and "Greenfang Mountains". Due to this fact, the author will only discuss the exceptional examples in the following.

2) Names of creatures

Example:

English: Now wielding both relic weapons, Lucian fights to slay the undead and cleanse the souls of the Shadow Isles.

Chinese: 现在, 装配着两把遗物武器的卢锡安, 为了屠 杀亡灵生物和净化暗影岛的灵魂而战。

Translation strategy: Naturalization.

"The undead" in LOL refers to evil creatures living in the Shadow Isles. In the Chinese version, it is translated into “亡 灵生物”, using the strategy of naturalization. “亡灵” is a Chinese CSI with reference to the souls of the dead as in “汝 为子孙, 不能有益先人, 而反累辱亡灵, 可吒头为吾陈 谢” in which “亡灵” means the souls of the passed ancestors. However, the connotation of “亡灵” has been extended through Chinese popular literatures, many of which used “亡 灵” to indicate some evil and dark creatures. This part of meaning in “亡灵” is a match with “The Undead”, and possibly due to this reason, the translator used naturalization: to use an CSI from the target culture to represent the CSI in the source culture.

\section{B. Material CSIs}

\section{Example:}

English: With Lestara's guidance, Sona discovered a deep connection with the instrument which Lestara called an "etwahl". In her hands, it played tones which stilled or quivered the hearts of those around her.

Chinese: 在乐斯塔拉的谆谆教导下, 娑娜发现了自己内 心深处与古琴的共鸣。乐斯塔拉将那把古琴定名为 “叆 华”。

Translation strategy: Autonomous creation.

"Etwahl" is the name of the instrument Sona plays. It is a created word with beautiful meaning. "Etwahl" is also the weapon players used to fight against another in LOL game. For CSI like this, it worth careful translation as game players may not pay much attention to the background places or climate, but will certainly remember those they may encounter in game. Naming the instrument “叆华”, the translator used the strategy of autonomous creation. “叆” in Chinese is often used to refer cloud, or fragrance. “华” in Chinese, when connected with cloud, is the colored ring of light when sun light passes through thin cloud. The translator chose to create “叆华” to represent the beauty of "Etwahl”. Besides, this translation is easily for players to read and remember compared to those translated through orthographic adaptation.

\section{Social CSIs}

For social CSIs, they are most names and titles of champions in LOL. Names are mainly orthographically translated. Every champion in LOL has a title. The title shows either the personalities or the skills of a champion. The accuracy of the title translations can influence players' 
understanding and choice to champions. 116 champion titles together, 84 of which are translated through literal translation, or literal translation plus orthographic adaptation.

Literal translation, as defined by Wikipedia, is the rendering of text from one language to another one word at a time. It is despised by translation theorists as literal translations are often arbitrary and machinery. Wang Dongfeng, a Chinese scholar who made contributions to the study of culture-specific items at home stated clearly that literal translation, though one way to deal with culture-specific items, is better to be forbidden as its translations are the worst as they can be. However, here the author is studying a completely new type of culture-specific items which scholars before have never thought of - the fictional culture-specific items in games. Usually when translating a culture-specific item, translators have to consider all the cultural aspects both from the source and the target culture. But for fictional culture-specific items, the translation jobs become comparatively easier as the only cultural meaning worthy to be considered is right in the game text, and the meanings and connotations of a game fictional culture-specific item are pure and simple. Since the culture-specific items are newly-created, their source texts can be seen as new to source readers. Similarly, translators can directly translate them into new Chinese items for potential players to learn and absorb. This explains why literal translation is favored in dealing with fictional game culture-specific items.

However, the rest 32 culture-specific items do fall into several translation strategies put forward by Aixela due to different conditioning factors.

For example, The Darkin Blade is the nickname or the title of Aatrox. Aatrox in LOL is a champion in the region of Runeterra. In ancient times, Aatrox was a mighty champion of Shurima, and he led to many victories against the rebellion of Icathia. Though his army defeated the rebellion, they have changed over years of years of fighting. Without external threats, Aatrox and his army, the self-described Sunborn, began to clash with one another, and eventually this became the war of the ruins of the world. Some mortals fleeing the conflict came to know them instead by a new and scornful name: the Darkin.

Based on the background story, it is clear to see that "The Darkin Blade" represents no blade but a champion, and "the Darkin" stands for a group of warriors who led the world to ruin. In this case, "the Darkin" is embedded with evil or horrifying meaning. The official translation of "the Darkin Blade” is “暗裔剑魔”. In dealing with its translation, the translator first literally translated "darkin" and "blade" into “暗” and “剑”, and then added extra explanation “裔” and “魔” to show the readers or LOL players that "the Darkin Blade" is, first, a champion; second, an evil spirts.

This translation can be explained through several aspects. First, the function of the source might influence the translation. In this case, "The Darkin Blade" is the title of a champion, so its basic function is reference. Since it is a reference of a champion, it might be more appropriate to if the translation sounds more like a name of a champion instead of a blade. This could probably explain why translators add “裔” and “魔”. Besides, the title has expressive function. "the Darkin" was once "the Sunborn". They were noble and well-respected. It is likely that translators deliberately add “裔” to stand for their previse nobleness. The translation can also be analyzed from the perspective of Chinese culture. “魔” in is a culture-specific item in Taoism in Chinese culture. In Taoism, “魔” and “仙” are equally powerful. “仙” is responsible for moralization and blessing, while the main job of “魔” is punishment. "The Darkin Blade" shares the same job with “魔”, and this cultural connotation might be the reason of the translation.

Some are translated through the strategy of naturalization. In LOL, "The rabble rouser" is the title of Gragas. Gragas is an alcoholic who puts more importance to drinking than fighting. He takes a keg almost wherever he goes, and he loves creaking heads just as much as creaking kegs. Because of his temperamental nature, whenever he goes out for drinking, he goes alone. He has never truly drunk, which puzzles him a lot. In search of a ale which can send him into the state of intoxication, he set foot on a journey to the continent of Freljord. In a great howling abyss, Gragas finally found the ingredient he wanted, a flawless shard of ice. With the ice, he made the ale he always desired. Under the spell of his new concoction, Gragas headed for civilization, eager to share the fermented fruits of his labor. As fate would have it, he blundered into a deteriorating negotiation between two tribes discussing an alliance with Ashe. Though Ashe welcomed a break in the tension, the other warriors bristled at the intrusion and hurled insults at the drunken oaf. True to his nature, Gragas replied with a diplomatic headbutt, setting off a brawl matched only in the legends of the Freljord. It was a fight. It was a chaos. But when the fallen from that great melee finally awoke, Ashe proposed a friendly drink as an alternative to fighting. With their tempers doused in suds, the two tribes, formerly on the brink of war, bonded over a common love of Gragas' brew.

Gragas is an alcoholic. He is physically strong. He is rude, aggressive, and a trouble maker. However, at the same time, he is straightforward and persistent. He is a man with a good heart. In English, a "rabble rouser" in originally refers to someone who causes chaos by inciting lowlife to rebel or riot. It is a comparatively negative phrase, often implying politicians or warlords.

In Chinese culture, a figure like Gragas is no stranger as many literatures portrait figures like him. For example, Li Kui, one of the heroes in The Water Margin, nicknamed as the "Black Whirlwind". He is impetuous and with a violent temper but straightforward and honest. He enjoys gambling and drinking, he sometimes killing ruthlessly, yet he is loyal to the code of brotherhood. This complex personality also appears in Zhang Fei, one of the main characters in Romance of the Three Kingdoms. He lost the city of $\mathrm{Xu}$ Zhou only because he was drunk and was beating the son-in-law of Lv $\mathrm{Bu}$. For characters fancies drinking, Chinese has a special item for them - “酒桶”. Literally, “酒桶” refers to someone who is addicted to alcohol, but with the influences of literature, “酒桶” is attached with the meaning of describing a certain type of people who are physically strong and often simple-minded, addicted to alcohol, and with the great virtue 
of loyalty.

Both the direct and indirect meaning of “酒桶” fit the description of Gragas, who is titled as "the Rabble Rouser". Based on the similarities between “酒桶” and the nature of "the Rabble Rouser", the translator applied naturalization to deal with its translation.

The Nine Tailed-Fox is the tile of Ahri, a hungry memory hunter in the region of Ionia. She was abandoned in the snowy woods of northern Ionia and was accepted by a pack of icefoxes who taught her to hunt. However, after an accidental killing of a hunter, Ahri found that she received flashes of memory from the soul she consumed. Soon she was addicted to memories from others and became monstrous in people's eyes. Aware of her crimes, she was in guilty and sealed herself in a cave. Years later she emerged, though sometimes, driven by her desire, kill and eat memories again, she determined to see the world once again with her own eyes instead of other people's memory.

Based on the background story, the Nine-tailed Fox is an evil persona yet with righteous awareness. She is pretty. She has nine tails, and she can manipulate other lives' mind. This description fits a legendary Chinese creature - “九尾妖狐”, and it is the cultural aspect which determines the choice of translation strategy.

“九尾妖狐” originates in ancient Chinese legends, and was first dated clearly in The Classic of Mountains and Rivers, as described:

“青丘之山，有兽焉，其状如狐而九尾，其音如婴儿， 能食人, 食者不盅。青丘国在其北, 其狐四足九尾。”

This pictures a folk-like creature who has nine tales. This is the same with the look of the fox Ahri. With time goes by, people legend nine-tailed foxes with new stories, and many portrait the nine-tailed foxes to be beauties with the magic power, and they are often described as both ruthless and innocent. With the huge similarity between these two, the translator directly use “九尾妖狐” to represent “the nine-tailed fox", and the translation strategy employed is naturalization. However, "Ahri" is the champion came into play when Korean Server began to use. Normally players consider the champion Ahri is related to Korean. However, the Korean “九尾妖狐” is no difference from the Chinese “九尾妖狐”, so the translation stays the same. But in this case, the translation strategy changes. It would be limited universalization which means to adopt the culture-specific item from a culturally similar country to translate the source text.

Deletion is also a method favored by translators. "The Seneschal of Demacia" is the title of Xin Zhao. Xin Zhao is a loyal servant of Jarvan III. Coined the Seneschal of Demacia, Xin Zhao is the personal steward of the Lightshield Dynasty. Years ago, Noxus was renowned for a spectacle called The Fleshing. It was a gladiatorial event with a cruel twist: as a fighter won matches, his number of opponents fought simultaneously would increase. This meant eventual death for every contender, but with unparalleled glory. Xin Zhao, known then as Viscero, was slated to face 300 soldiers, nearly six times the previous record. This was clearly meant to be his final match. Jarvan II, hearing of this unprecedented feat, infiltrated the arena to offer him an alternative: serve
Demacia and punish those who ultimately sentence him to death in exchange for his freedom. Xin Zhao accepted, astonished that a king would risk his own life on his behalf. Under the cover of a prearranged Demacian assault on Noxus, Jarvan liberated Xin Zhao and his 300 opponents. During their retreat, Xin Zhao took a poisoned dart meant for Jarvan. This act of loyalty, from a man who vowed no allegiance, earned Xin Zhao a spot at his side until the day the king died.

Xin Zhao has devoted his life to the royal family of Demacia, for which he earns the title of "The Seneschal of Demacia". It is apparent that translators translate this title through literal translation, as “总管” is correspondent with "Seneschal". However, translators do not translate “Demacia” into “德邦” instead of “德玛西亚”. The reason why translators use deletion might because of the function of the title.

The function of the source is also an influential factor to translations. The functions of titles vary from one another. Some are similar to champion names, being the referents of champion. Some contain expressive function, with indication of the personalities of champions. Some have informative function, with which people could know details such as weapons or appearances of champions. "The Seneschal of Demacia" is more of an introductory title to tell people who is he. In this case, literal translation would be appropriate for the fiction item. Besides, as mentioned before, translators have an unsaying rule that the translations should not too long to cause difficulty in read or memorization. This might explain why translation employs deletion.

Of 116 champion titles together, 91 are translated into four-character Chinese titles. The simplest reason to explain this translation phenomenon is that most source champion titles are three or four letters, and the upper analysis has already proved that most titles are literally translated. In this case, a three-or-four-letter item is reasonably translated into a four-character Chinese title. However, there are deeper cultural factors behind these translations.

Analyzing from the cultural aspect, it can be assumed that Chinese like using four-character expression based on the unique Chinese expression - four-character idioms and proverbs. The origins of four-character idioms and proverbs can be extended to a long thesis. Here the author mainly explains why Chinese, hereby to refer translators in this thesis, fancy the use of four-character.

The first reason might lie in the characteristics of Chinese tones. Unlike other languages, Chinese is a tonal language with four tones - level tone, rising tone, falling-rising tone, and falling tone, and these tones are often paired in daily expressions. In this case, a four-character expression could adjust to many tonal combination and changes, so as to provide a beautiful intonation for both listeners and speakers.

The second reason could be related to the historical custom. It is not rare that Chinese like using four-character expressions. Dated to the Spring and Autumn Period, The Book of Songs, the first anthology of verses and poetry in ancient China, collected verses and poetry which mainly adapt forms of three or four-character as one sentence with rhymes. The verses and poetry in The Book of Songs are also accepted by many as the origins of Chinese four-character idioms and proverbs. At the same time, the wide use of 
four-character expressions has, in return, proven to have vast potential to express abundant meaning by this concise form. Translators could be influenced by the fancy of four-character expressions instinct during the translation process.

Some champion titles in source text do not have a clear indication showing that this title is a reference of a champion. For example, "The Darkin Blade" is more like a title for a blade. Inferring from the literal meaning, it seems that "The Darkin Blade" is to indicate a very evil blade which may have dark power to bring disaster to the world. However, the fact is "The Darkin Blade" is a champion and in Chinese, it is translated into “暗裔剑魔” with a word “魔” to personalize the title. Similarly, "The Loose Cannon" is not a cannon but a champion whose weapon is gun and cannon, and it is translated into “暴走萝莉”.

Another characteristic the author noticed is that Chinese translations are more sexually clear than the source English titles. 11 champion titles are translated into Chinese with added word or words to refer to the sex of the champion which is not indicated by any word in the source, and they are all female champions. "The Sheriff of Piltover" is translated into “皮城女警” with the word “女” indicating the gender of the sheriff. Feminist translation scholars strongly resist the gender discrimination. It is possible that in order to avoid confusion and dissatisfaction caused by unclear genders, translators with foresight make the translations sextually clear so as not to offend potential female players.

It can be concluded that for the title translation that when it comes to the CSIs familiar to players, translators can employ any strategy to make sure the translated versions are cool and in the same format to attract players.

\section{CONCLUSIONS}

From the above analysis, the author can draw two conclusions.

First, the most used translation strategies of game CSIs are orthographic adaptation and linguistic (non-cultural) translation. Those complete newly created CSIs would be translated through orthographic adaptation, while those created based on common words would be translated through linguistic (non-cultural) translation.

Second, the CSIs in game text can be divided into two parts. One is those in the background story. Though

completing the game, these CSIs are strangers to game players as few players would read them, thus their translation would follow the rules of faithfulness, expressiveness, and elegance. But the other part of CSIs are those game players would read when entering the game, such as the names of summoned heroes or skills. For these CSIs, the priority for translators is to attract players, thus their translation may not be true to the original meaning. But with flexible adoptions of Aixelá's translation strategies, they are all appealing.

\section{REFERENCES}

[1] B. A. Lefevere. Translation, History and Culture, Shanghai: Foreign Language Education Press, 1992.

[2] B. Susan and A. Lefevere, Constructing Cultures: Essays on Literary Translation, Shanghai: Shanghai Foreign Language Education Press, 2002.

[3] X. Zhang, A Report on C-E Translation of Culture-Specific Items in Publicity Text, Shenyang Normal University, 2017.

[4] J. F. Aixela, "Culture-specific items in translation," in Translation, Power, Subversion, Roman Avarez M. Carmen-Africa Vidal Eds. Beijing: Foreign Language Teaching and Research Press, 2007.

[5] M. Chen, A Study of Foreignization and Domestication in Translating Culture-Specific Items in Tanxiang Xing, Shandong University, 2017.

[6] Y. Chen, Study of the German Translation of Culture-Specific Elements from the Perspective of Functional Translation Theory-on the Example of the Novel Heavy Wings, East China Normal University, 2017.

[7] N. Eugene, Language, Culture, and Translating, Shanghai: Shanghai Foreign Language Education Press, 2005.

[8] N. Eugene, Toward A Science of Translating, Shanghai: Shanghai Foreign Language Education Press, 2007.

[9] L. Mu, On Back Translation of Chinese Culture-Specific Items, North China University of Water Resources and Electirc Power, 2017.

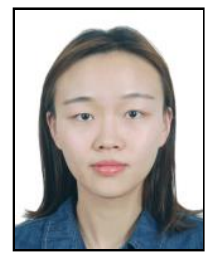

translation.

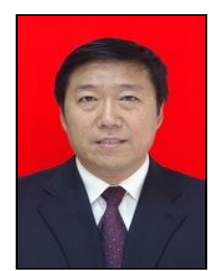

Shi Xinyan was born in Jiangsu, China in 1993. She earned her bachelor's degree in art of English at Schoo of Foreign Studies, Northwestern Polytechnical University, Xi'an, China in 2016.

She is presently a postgraduate student at Northwestern Polytechnical University, China. Her research interest covers cross-cultural communication, game localization, cultural translation, and machine

Tian Jianguo was born in Liaoning China in 1959. He earned his master's degree of education in Emporia State University, Kansas, USA in 1995.

$\mathrm{He}$ is presently a professor at School of Foreign Studies, Northwestern Polytechnical University, Xi'an, China. His research interest includes sociolinguistics, corpus linguistics, applied linguistics, and machine translation. 